\title{
CANALIZAR O FLUXO: LIDANDO COM A MORTE NUMA RELIGIÃO DE MATRIZ AFRICANA
}

Gabriel Banaggia ${ }^{1}$

${ }^{1}$ Pontifícia Universidade Católica do Rio de Janeiro (PUC-Rio), Programa de Pós-Graduação em Ciências Sociais (PPGCIS), Rio de Janeiro, RJ, Brasil

Fiéis de muitas e distintas religiões de matriz africana têm um ditado cujas múltiplas versões poderiam ser sintetizadas do seguinte modo: "Em nossa tradição, tem jeito para tudo, menos para a morte". Contudo, ao menos em algumas dessas práticas e para algumas poucas pessoas, é possível enganar até mesmo a morte, ainda que em graus variados. Por vezes isso ocorre com o auxílio de pessoas mortas, enquanto em outras ocasiões a medida é feita à revelia delas: sem seu conhecimento, consentimento ou

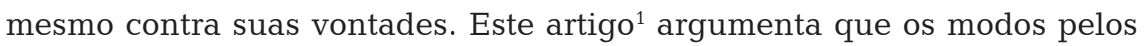
quais participantes destas religiões obviam a aniquilação dependem da manipulação satisfatória de uma energia vital que existe potencialmente em todas as coisas. Para tanto, e já que os espíritos de gente morta podem ser concebidos ora como compostos por esta energia, ora como agentes de sua extinção, lidar com eles é primordial para a sobrevivência. Pessoas mortas, no entanto, se comportam e operam sob muitos aspectos como as vivas, daí, para melhor compreender seu modo de existência, é preciso antes se voltar para as maneiras pelas quais fiéis canalizam a força vital para protagonizar e receber curas durante as cerimônias e também para seguirem suas rotinas, igualmente influenciadas por sua religião. Estes argumentos serão explicitados gradativamente no decorrer do texto, fazendo recurso a situações etnográficas derivadas principalmente de uma destas religiões, a começar pela vinheta que se segue.

\section{A mão do morto}

A cerimônia estava prestes a terminar, e parecia ter sido um sucesso retumbante. Tratava-se de uma ocasião delicada, já que diferentes grupos que nem sempre congraçavam haviam comparecido ao local. Quando a última entidade deixou o corpo da adepta de maior prestígio da casa, 
entretanto, a iniciada não voltou a si. Permaneceu estatelada no chão, sem fazer movimento algum, como se estivesse desmaiada - ou pior. Foi preciso que o pai-de-santo que conduzia o evento soasse a campa sobre a cabeça da adepta para que ela retornasse a si, sem lembrança do que havia ocorrido. Posteriormente, o restante da congregação conjecturava à boca pequena os motivos da queda. Seria mesmo então preciso que a adepta realizasse um novo trabalho para renovar suas forças? Teria a mão do morto que repousava ainda sobre sua cabeça se tornado enfim uma influência malfazeja? Ou estaria agora, finalmente, o espírito do curador que iniciara toda aquela congregação cobrando o preço por seu ritual funerário não ter sido inteiramente concluído?

O evento em questão era uma festividade de jarê, uma religião de matriz africana elaborada no Brasil. O jarê, que pode ser considerado uma espécie de candomblé de caboclos (Senna 1998:36, 74-76, 116-117), envolve festas em que praticantes cantam, dançam e em geral permitem que as entidades das quais mais se aproximam se manifestem em seus corpos. Frequentemente há repastos, rituais ou não, e, ocasionalmente, sacrifícios de animais quando em ocasiões iniciáticas. As cerimônias têm duração variável, em torno de cinco a dez horas seguidas num único dia. Às vezes podem ser repetidas em mais de um dia consecutivo, em geral dois ou três, ao contrário do que ocorria no passado, quando podia haver até nove dias seguidos de festividades. Ao longo de cada celebração pessoas sensíveis à ação das entidades costumam chegar a receber até uma dezena delas por noite, no total podendo haver, nas casas com maior número de fiéis, até perto de uma centena de incorporações distintas numa única festa.

O jarê, diferentemente do candomblé que surgiu no litoral do Brasil, se desenvolveu e se perpetuou apenas na Chapada Diamantina, região serrana, de clima semiárido, localizada no coração geográfico do estado da Bahia, no nordeste do país. O povoamento não indígena dessa área interiorana teve início ainda no século XVII, mas os processos migratórios que mais marcaram a região aconteceram predominantemente no final do século XVIII e na primeira metade do XIX, com a exploração de minério por meio do garimpo. A principal mercadoria dali extraída foi o diamante, que empresta seu nome à Chapada e marca uma divisão histórica dos municípios pertencentes à região conforme apresentassem ou não possibilidade de extração da pedra. As cidades mais antigas pertencem assim à região das lavras, no centro da Chapada Diamantina. O crescimento dos povoados no entorno se deu em função da necessidade de prover gêneros agrícolas às áreas de garimpo, bem como encontrar uma opção econômica viável nos períodos de intervalo entre os ciclos mineralógicos favoráveis, 
dando surgimento a uma zona propriamente agrícola na qual não havia cata do diamante.

O desenvolvimento histórico do jarê acompanhou esse mesmo sentido, sendo as cidades de Lençóis e Andaraí, nas lavras, consideradas o berço desta religião. ${ }^{2}$ Para essas cidades foi levado à força, no século XIX, grande contingente de mão de obra escrava, composta não só por gente africana trazida diretamente da costa, como também por sua descendência vinda de outras regiões do Brasil, dando origem em seguida a uma população local considerada largamente mestiça em função de afluxos de garimpeiros do interior do estado de Minas Gerais, região conhecida pela mineração aurífera, e da área do Recôncavo, no próprio estado da Bahia, só que mais próxima do litoral. O fato de que o jarê se desenvolveu nas Lavras Diamantinas conecta sua história intrinsecamente à da região, marcada pela extração de pedras preciosas até bem recentemente (Senna 1998:41-43, 49-51).

Buscando uma alternativa para o baixo rendimento econômico do diamante nos últimos anos, moradores da cidade de Lençóis obtiveram sucesso em dirigir suas atividades para a prestação de serviços, principalmente o ecoturismo. O casario da cidade foi tombado pelo patrimônio histórico nacional em 1973, e em 1985 foi decretada uma área de conservação na forma de um gigantesco Parque Nacional abrangendo a serra do Sincorá, medida que serviu para frear a depredação natural que a área continuava a sofrer em função de um adventício garimpo altamente mecanizado que substituiu o garimpo tradicional feito artesanalmente. Além disso, ambas as formas de proteção contribuíram para colocar a região de uma vez por todas no mapa dos melhores destinos ecoturísticos do mundo (Brito 2005:299).

\section{A vida da terra diante da morte do solo: uma metafísica telúrica}

Com a transição da economia local para o turismo ecológico de aventura, houve crescente demanda por guias que conhecessem os caminhos traiçoeiros das serras, capazes de levar visitantes por trilhas que por vezes duram alguns dias para percorrer até chegar a magníficas cachoeiras, profundas grutas, lagos subterrâneos e platôs com paisagens fascinantes. Os membros da população tradicionalmente garimpeira encontravam-se de algum modo já preparados para se tornarem guias pelas matas e montanhas, cultivando o hábito de caminhar por horas a fio e transmitindo o conhecimento da topografia chapadina, ambos os temas caros ao jarê por tratarem diretamente do solo, como será visto adiante. 
O trabalho dos garimpeiros, como em grande medida passou a ser o caso também com o dos guias, envolvia uma íntima conexão com a terra. Sua própria sobrevivência dependia de seu conhecimento da geografia da região e das técnicas do garimpo, que incluíam alteração de cursos de rios, realização de escavações e prospecções nas grunas - grutas submersas com bolsões de ar para respirar -, e informação a respeito dos diferentes resíduos rochosos que precisavam revolver na cata dos diamantes. Similarmente, seu trabalho os levava a caminhar muitos quilômetros pelas serras e matas da Chapada, abrindo trilhas, construindo tocas nas quais por vezes pernoitavam, escalando paredões rochosos bastante íngremes e elevados (Toledo 2001:102-13; Toledo 2008:69-76, Lima \& Nolasco 1997:19).

Enquanto os homens andavam por longos trechos em seu trabalho diário no garimpo, as mulheres também se locomoviam consideravelmente em seu cotidiano, fosse para pescar, lavar roupas ou buscar lenha. Assim, não é por acaso que nos dias de hoje abundem entre a população de Lençóis expressões e considerações existenciais relacionadas à ação de caminhar. Passou então a ser comum dizer de alguém confiável que se trata de uma pessoa que "pisa seguro", e para falar sobre a exemplaridade da conduta de uma pessoa, basta dizer que se "pisaria onde ela pisar". Reproduzir as ações de alguém é querer "trilhar seu caminho", aproximar-se de alguém é "andar junto", e obter vantagem às custas de uma pessoa é "derrubá-la". Elogiar um comportamento comedido ou reprovar um afobado envolve lembrar que "quem corre cansa e quem anda alcança", e são muitas as referências que fazem para falar de problemas na vida como obstáculos a serem transpostos num trajeto, como no ditado: "Isso não é muro alto que não dê para pular, nem rio fundo que não dê para atravessar" (Gonçalves 1984:115).

Mais do que apenas figuras de linguagem, estas formas de falar a respeito do seu mundo, que continuam ativas na contemporaneidade, são acompanhadas por disposições discursivas e corporais bastante específicas acerca de seus lugares de habitação e suas cercanias. É comum referir-se a alguém pelo local onde mora, bem como falar do passado lembrando sempre o lugar preciso onde a pessoa que fala então se encontrava - preferencialmente evocando-o na mente de quem ouve. Da mesma forma, habitantes mais antigos de Lençóis frequentemente atribuíam sua marcada longevidade ao fato de muito terem caminhado ao longo de suas vidas. Exemplos como estes poderiam ser multiplicados, mas para os propósitos do presente argumento não seria exagero dizer que, de determinado ponto de vista, a experiência do movimento é crucial na vida da gente nativa da Chapada, marcando a profundidade temporal de um modo sempre espacializado. 
As famílias no passado compostas por garimpeiros e hoje por guias das trilhas formam a parte mais substantiva do povo de santo dos jarês das Lavras Diamantinas. As mencionadas disposições diante do solo conectam-se com as elaborações cosmológicas e rituais que o jarê similarmente nutre a respeito da terra e de sua composição, de modo bastante parecido como fazem os candomblés litorâneos no Brasil (Bastide 1958:37, 74, 85, 270 nota 27; Barbosa Neto 2012:45, 143-150 e nota 104; Flaksman 2014:14, nota $7,90,98,266)$. Os passos das pessoas ao dançarem devem ser precisos e estar de acordo com o estilo das entidades que visitam os terreiros a cada momento, chamadas todas, de modo praticamente indistinto, de "caboclos". ${ }^{3}$ As substâncias decorrentes das oferendas rituais devem ser depositadas no centro das casas de culto e ali absorvidas pela terra, passando a fazer parte da força do local, e colocando-a em movimento. O repositório de energia ali concentrada jamais pode ser tirado do lugar, fixando em torno de si a comunidade religiosa e sobretudo sua liderança espiritual, responsável pelos procedimentos de manutenção mística do local.

Essa série de disposições proxêmicas em relação ao chão e à terra pode ser caracterizada como parte de uma "metafísica telúrica"4 que, se não é de modo algum exclusiva ao jarê, encontra na Chapada Diamantina um solo particularmente apropriado para elaboração. O telurismo místico do jarê pode ser de saída entrevisto na ação das entidades mais velhas, explicitamente ligadas à terra, como Nanã Borocô e Abaluaê, que quando incorporam nas pessoas imediatamente caem prostradas ao chão. É costume, quando se começa a cantar para esses espíritos, que todas as pessoas presentes levem ao menos os dedos de uma das mãos ao chão, mantendo contato com o solo. Quando chegam ao pagodô (o maior aposento dos templos de jarê), essas entidades se dirigem, engatinhando, até próximo dos atabaques, despejando-se diante delas água e dendê, que misturam com a terra batida que constitui o chão do salão, dando origem a uma lama que as próprias entidades manejam e espalham sobre seus corpos, especialmente nas costas das mãos e braços

Esse fenômeno amplia outro que é minimamente reproduzido ao longo de todo jarê, quando a dança das pessoas descalças no chão de terra, às vezes molhado (por água ou por transpiração), o desgasta parcialmente, havendo o cuidado para que não fique escorregadio demais a fim de evitar derrapagens. Assim como o derretimento progressivo das velas - objetos eminentemente verticais que parecem se tornar cada vez mais próximos do chão, sendo tragados por ele - transmite a ideia da permeabilidade do solo, muitas das substâncias utilizadas e produzidas nos rituais terminam sendo vertidas sobre a terra do pagodô e por ela assimiladas, sobretudo o sangue, mas igualmente o dendê, a aguardente, o mel, a água, o suor. A energia 
mobilizada nos e pelos rituais, que simultaneamente se constitui de e é transmitida por essas diversas substâncias, penetra no solo da casa de culto e passa a fazer parte dele, sendo continuamente revolvida e readministrada por e em outras ações rituais, como no exemplo da lama.

Do mesmo modo, jamais se permanece calçado depois de ser tomado por uma de suas entidades, já que os espíritos incorporados se recusam a dar qualquer passo caso seus pés não estejam em contato direto com o solo. Existem mesmo momentos, observados com bastante gosto e atenção, em que as entidades incorporadas num jarê abandonam momentaneamente sua conexão com o solo, ou fazem com que outras pessoas a percam. Ainda que geralmente sua coreografia seja executada quase exclusivamente perto do chão, alguns homens em particular, quando em manifestação de seus espíritos, acrescentam a ela pequenos saltos, por vezes tirando ambos os pés do chão, ao mesmo tempo em que dobram os joelhos. Esses passos são recebidos pela assistência com bastante alegria, considerados divertidos e belos.

Tal avaliação se deve também ao risco que se aceita correr não só de cair, como também de abandonar o chão por alguns instantes. De modo similar, uma saudação feita com muito gosto por determinadas entidades, em geral reservada a crianças mas não limitada a elas, envolve tirar uma pessoa do chão com um forte abraço, dobrando o próprio corpo para trás enquanto a levanta. Fiéis do jarê comentam que esta é uma forma de transmitir saúde à pessoa cumprimentada, enfatizando uma determinada possibilidade de canalização que ocorre quando o seu próprio contato com o chão passa a depender de e a ser feito por uma entidade. Numa inversão dessa configuração, lembram que se deve evitar pular por cima de uma pessoa quando esta se encontrar deitada no chão, especialmente no período do resguardo, sob pena de abrir o corpo dela a influências danosas.

Também em função dessa metafísica telúrica, compreende-se bem o receio da população nativa da Chapada Diamantina com a morte do solo ocasionada pelo avanço do garimpo mecanizado na região até o final dos anos 1990. Conta-se, entretanto, que quando prospecções à procura de pedras preciosas eram feitas nas proximidades do terreno de importantes casas de jarê, tudo que se encontrava era carvão em vez de diamantes. Esses fracassos, fossem eles considerados resultado da ação mística das lideranças do jarê na proteção de seu território, fossem pensados como uma resposta da própria terra nos locais onde sua força é mais concentrada aos ataques que sofria, evidenciavam a importância da vida do solo. Além de ser a fonte direta do sustento da população garimpeira tradicional, cujo garimpo menos invasivo jamais resultou na destruição radical do solo comprovada pelos grandes bancos de areia deixados pelo garimpo meca- 
nizado, nem na consequente diminuição das espécies animais e vegetais da região, o povo do jarê depende, para a manutenção de sua religião, da força que a terra condensa.

\section{Forças e suas formas: modulando intensidades}

Todas as entidades mobilizadas no jarê, em especial as que se incorporam no povo de santo, de determinado ponto de vista, podem ser pensadas como forças em estado concentrado, capazes de participar no cotidiano dos seres humanos, entre várias outras formas, por meio de manifestações em seus corpos. Com o passar do tempo, com o cultivo do hábito de recebê-las nas casas de culto e com o surgimento de intimidade entre pessoas e seus espíritos, as forças - que as entidades simultaneamente são e têm - vão sendo sedimentadas nos corpos de quem as recebe, concentradas neles: os caboclos que o povo do jarê manifesta são como 'precipitados' pessoais de espíritos-força mais absolutos, no sentido químico do termo. ${ }^{5}$ Vários entes do mundo, como os outros animais, as plantas e determinados objetos, a exemplo de pedras específicas, também existem enquanto produtos de certa 'destilação' das forças abrangentes com as quais os seres humanos travam contato, assumindo muitas vezes formatos específicos e consistências determinadas que facilitam a interação.

Os rituais do jarê favorecem a utilização de inúmeras substâncias literalmente fluidas - e entre estas há especial atenção às viscosas e às nubíferas -, como os perfumes, a cachaça, o vinho, a água, o suor, a saliva, o sangue, o dendê, o mel, comidas como o vatapá e o caruru, o talco, o pó de pemba, as cinzas, a pólvora, o enxofre dos foguetes, o incenso, e mesmo o hálito (da palavra, das cantigas e do arfar que evidencia o esforço em perseverar contra o cansaço), de modo similar ao que acontece em várias outras religiões de matriz africana (Souty 2007:455). Todas essas formas que as forças do jarê podem adquirir para serem postas em circulação e transmitidas são capazes de se espalhar nas pessoas presentes, seja melando-as ou lambuzando-as, seja aspergindo-as ou pulverizando-as. Por outro lado, outras substâncias também granulares cujas partículas não ficam em suspensão - como farinhas, milhos e feijões - são reservadas à alimentação das entidades não incorporadas e também aos rituais de iniciação, fazendo com que os corpos de quem se inicia fiquem abertos, mais porosos às transferências, até que voltem a ser fechados e protegidos pelas primeiras.

O sangue, sobretudo o sacrificial, é uma das principais substâncias responsáveis pela transmissão da força que o jarê mobiliza, sendo também 
sua forma concreta por excelência, justamente por ser, por definição, o fluido vital primeiro. O sangue que é derramado sobre o povo de santo e oferecido às entidades simultaneamente é e carrega consigo a força que a autoridade ritual coloca em marcha para realizar curas, para conectar ou separar pessoas e espíritos. Comenta-se como é fundamental que, após o ritual de iniciação, as pessoas que acabam de se vincular à casa de culto durmam aquela noite com seus corpos e vestimentas marcados pelo sangue coagulado proveniente das oferendas, que é removido na manhã seguinte com os banhos que encerram os trabalhos.

O sangue residual que é derramado no centro dos salões de jarê ao final dos rituais iniciáticos é espalhado e coberto com terra, até que faça parte, literalmente, da força que emana do chão do terreiro - força esta que é o próprio chão - e do conjunto de objetos rituais que há enterrados nele. Em algumas casas, o sangue sacrificial é também consumido diretamente por quem frequenta o jarê durante as cerimônias em homenagem a entidades caras à liderança do local, sendo derramado durante a matança numa bacia específica e misturado com mel e com alguma bebida, em geral cachaça. O preparado, que é imediatamente oferecido em pequenos copos a quem estiver presente para que se bebam alguns goles - alertando-se que se deve fazê-lo com reverência -, recebe justamente o nome de "sangue real". O sangue sacrificial que idealmente precisa ser vertido nos rituais sintetiza assim muitas das modulações que as forças podem adquirir ao serem manipuladas: trata-se de uma substância fluida, transferível, transpositora, diluível, condensável, sápida.

Inversamente, o sangue pode ser também uma substância utilizada com grande propriedade em procedimentos místicos que tenham fins contrários à vida, como no caso do sangue resultante de atos de violência. De qualquer forma, a situação mais comum em que o sangue figura como uma espécie de força oposta à das entidades reverenciadas nas festas pode ser observada no tabu da presença de mulheres menstruadas nas cerimônias. $O$ povo de santo comenta que mulheres que estejam em seus períodos devem evitar frequentar as festas de jarê, já que, por vezes, a mera proximidade dos caboclos com uma pessoa menstruada é o bastante para drená-los de sua energia, fazendo com que seus aparelhos (como são chamadas as pessoas ao receberem entidades) tombem desacordados no chão. Muitas jovens, desejosas de não perderem nenhum jarê, alteram a frequência de ingestão de pílulas anticoncepcionais de modo a fazer com que seus períodos não coincidam com as datas das festas, prática que, de todo jeito, é vista pelas pessoas mais cautelosas com boa dose de reprovação. Não é incomum que se diga de mulheres menstruadas, com algum eufemismo por se considerar 
um tema delicado, que se encontram "doentes", ou ainda que estão de "corpo sujo". Esta última designação também se aplica a quaisquer pessoas que tenham feito sexo recentemente, devendo passar pelos banhos propiciatórios anteriores à festa para que seu estado não seja nocivo às entidades.

Em comum com o primeiro caso, no segundo, os corpos das pessoas envolvidas passam a ser considerados "abertos", especialmente sujeitos às influências de forças perniciosas, em função da proximidade que se estabelece com o canal vaginal. Como o povo do jarê afirma, mesmo quando não menstruadas as mulheres têm maior propensão a e capacidade de fragilizar as entidades por possuírem em seus corpos um canal pelo qual há, de modo intermitente, passagem de sangue. O sangue menstrual é considerado substância especialmente adequada à realização e à quebra de feitiços, e sua óbvia conexão com a morte - ou, para dizer mais precisamente, com uma não vida - o qualifica para agir como uma força contrária de considerável intensidade, duplamente abortiva. Por compartilhar com esse sangue uma mesma via de passagem, a urina feminina, ao contrário da masculina, tem um similar potencial de neutralização energética, ao menos no que tange à sua aplicação contra feitiços. Há quem chame essa força, justamente oposta à energia vital dos caboclos, de abajé (termo que se estende igualmente ao estado da mulher que se encontra em seu período menstrual), sendo ela capaz de derrubar entidades nos salões de jarê por causa de seu excesso.

\section{Afastamentos necessários e aproximações arriscadas: os rituais mortuários}

As ocasiões rituais que tratam direta e indiretamente da morte de pessoas ligadas ao jarê evidenciam o modo como mesmo depois de deixar esse mundo é possível continuar agindo sobre ele. O ritual funerário por excelência no jarê é bastante comum ao dos candomblés (cf. Bastide 1958:135137; Elbein dos Santos 1975:231), chamado de axexê ou sirrum (pronunciado "serrum" na região). Quando qualquer importante líder da religião morre - em especial no caso de mestres do jarê, como são chamadas as pessoas que iniciaram outras que também criaram terreiros próprios -, um de seus pares é chamado para despachar a energia acumulada por quem faleceu, de modo a dissipá-la.

Na cerimônia em si, que pode durar alguns dias, sua força vital irá se condensar uma última vez, fazendo vibrar a cadeira que em vida lhe servia de trono no salão principal do templo. Conforme o povo do jarê comenta, as roupas e os ornamentos não são apenas formas que servem de auxílio no 
reconhecimento das entidades, mas objetos que em si mesmos ocasionam transformações e carregam algo da força pessoal de quem os possui, bem como de seus espíritos. Até por isso, as roupas de chefes de terreiro, que podem mesmo chegar a muitas dezenas, são nessa ocasião cuidadosamente descosturadas, bem como objetos pessoais de quem faleceu são quebrados, e o couro dos atabaques da casa é rasgado. Estes itens não são apenas formas de intensificar a proximidade de alguém com os espíritos: configuram materializações de parte dessa conexão e das forças envolvidas no processo de incorporá-los.

O rito em questão costuma marcar o final da existência de uma casa de culto específica, já que é comum que o centro energético que alimenta a casa de culto se enfraqueça e seja desfeito após a morte de quem zelava por ela. Essa operação pode mesmo ser feita pela própria chefia da casa de culto ainda em vida, caso pressinta a chegada do momento de sua morte e não deseje que haja sucessão em seu terreiro. Desfazer-se adequadamente de forças que não podem permanecer atuantes sem sua presença constitui também uma forma de não transmitir essas potências gratuitamente, impedindo que sejam legadas a alguém que não possa - ou não deva - recebê-las: é preciso empenho para se erguer uma casa de culto, e é ao longo da própria empreitada de criá-la e fazê-la crescer que se adquire ao menos parte do conhecimento necessário ao cuidado das forças envolvidas no processo.

A ausência de continuidade é assim comum na história dos templos de jarê, com casas sendo construídas quase sempre do princípio e demolidas após a morte de sua liderança, aquelas que prolongam sua existência constituindo-se numa exceção. Conforme diz o povo de santo, a própria casa é viva, como bem mostra o pulsar de suas paredes durante as cerimônias, animadas pelo toque dos atabaques. Nada mais compreensível, então, que a vida da pessoa que é responsável por ela se conecte de modo bastante direto com a estrutura física do local, sendo a solidez de uma espelhada na outra, e reciprocamente. Daí qualquer deterioração das edificações de um terreiro poder ser encarada com pesar, posto que sinal bastante direto do enfraquecimento pessoal de sua liderança espiritual. A estreiteza dessa conexão é mais um dos fatores que tornam a reutilização de uma mesma casa de culto por outra chefia religiosa algo consideravelmente arriscado todavia, uma possibilidade que, como qualquer risco no jarê, carrega consigo uma potencialidade para quem é capaz de lidar com ele.

Deixar de realizar a cerimônia de encaminhamento da pessoa falecida é uma alternativa que por vezes é concretamente empreendida, de modo que parte de sua força continue a animar uma casa de culto e a proteger o coletivo de iniciados. Essa força, contudo, pode vir a ser cobiçada por pessoas 
que desejam mobilizar sua potência em favor próprio, como no caso em que um jovem e ambicioso curador, que teve acesso às vestes cerimoniais de um grande pai-de-santo de uma cidade vizinha já falecido, experimentou vesti-las e, em consequência, acabou enlouquecendo por um tempo considerável. O resultado foi não só um castigo pela atitude desmedidamente audaciosa do jovem, mas também se tratou de um efeito bastante direto da desproporção entre sua força pessoal e aquela pertencente ao curador falecido, de certo modo presente em - ou acessível por meio de - sua indumentária. Num curioso caso oposto, conta-se que outro jovem pai-de-santo decidiu abandonar sua sina e realizar, ainda em vida, seu próprio rito funerário, desfazendo-se de suas vestimentas e objetos rituais. Algum tempo depois as entidades resolveram puni-lo pela tentativa e fazê-lo retornar ao jarê. Uma das consequências menos graves que resultou do processo foi ter perdido completamente o contato - mesmo após a abertura de uma nova casa de culto - com um dos espíritos que mobilizava.

Um outro ritual fúnebre precisa ser realizado em decorrência do falecimento de líderes do jarê, mas dessa vez pelas pessoas que foram iniciadas em sua casa, já que a influência que é exercida sobre elas não termina necessariamente com a morte de quem as iniciou, podendo, ao contrário, a partir de então, tornar-se involuntariamente nociva. O ato de "tirar a mão da pessoa morta" de suas cabeças, como é chamado este procedimento, costuma ser feito pela liderança que passará a ser responsável pelos rumos místicos de sua vida numa nova casa, efetivamente substituindo a mão da pessoa que faleceu pela sua. O procedimento ritual em si consiste num novo trabalho de iniciação, acrescido de etapas disjuntivas para marcar a separação entre a pessoa que se inicia e aquela que era responsável por ela. A mais comum destas é a queima do círculo de fogo, na qual se despeja uma roda de pólvora em torno da pessoa que é acesa ao final do rito usual. Afirma-se que nem toda pessoa necessita tirar a mão do morto - as mais velhas em especial costumam ser menos suscetíveis à ação de quem faleceu -, mas fazê-lo pode se mostrar um imperativo caso se esteja tendo problemas diagnosticados como de origem mística ou se deseje ter uma outra pessoa responsável pela continuidade de sua vida no jarê, podendo até resultar em uma mudança do local de habitação para acompanhar a rotina de uma nova casa de culto.

Pessoas que não realizam o ritual de remoção da mão de quem as iniciou acabam ficando mais sujeitas a sofrer o que o povo do jarê chama de "tombamento". Esse estado pode ser inicialmente entrevisto numa forma mais branda, quando as manifestações dos espíritos se mostram menos estáveis, dançando de forma vacilante, sem terem o passo seguro, propensos a desequilíbrios, tropeções e pisadas em falso. De modo mais acentuado, 
é possível que, após o término de uma possessão, uma pessoa sofra uma queda, em geral bastante brusca e violenta, ficando desacordada depois de ter sido desabitada pela entidade que até então reverenciava em seu corpo. Essa "breve morte" por ela sofrida normalmente consegue ser revertida em algum tempo pela chefia do terreiro, que se ajoelha junto do corpo e toca a campa, um sinete ritual, aos seus ouvidos.

A queda ritual do tombamento representa um sinal de enfraquecimento tanto do aparelho como de suas entidades, em geral fruto da ausência de conexão com alguém que faça iniciações. Ela pode também ser uma espécie de punição perpetrada pelos espíritos contra a própria pessoa que os recebe, de modo a marcar o descontentamento com alguma atitude por ela tomada ou por alguma obrigação que não tenha sido cumprida. O fato de que o afastamento da entidade impeça o retorno da pessoa à consciência, jogando-a ao chão, é agravado por deixá-la imóvel, em oposição ao movimento preciso, cadenciado e contínuo que marca o usufruto da vida e o cultivo da longevidade que o jarê tanto preza.

\section{Canalizando o fluxo: contra a morte, o movimento}

Como visto, as forças com as quais o jarê lida constantemente, e que em última instância são todas modulações específicas de um monismo energético de princípio, assumem determinadas formas para serem adequadamente postas em circulação, visando sobretudo a manutenção da vida. A ideia do movimento enquanto qualidade da vida encontra-se presente nos processos de cura que são centrais à economia ritualística do jarê. Todo processo de iniciação é também uma ação terapêutica, ou ao menos profilática, em potencial, regulando o fluxo vital das pessoas iniciadas e mobilizando-o de modo a mantê-las saudáveis, em especial visando a um equilíbrio - mais preciso seria dizer: um arranjo temporário menos instável - do grau de participação das entidades imateriais que as acompanham e constituem. Grande parte do trabalho ritual realizado nas cerimônias de cura e iniciação no jarê poderia ser descrita nos termos de metáforas vindas das ciências naturais, de modo a elucidá-lo para uma audiência que desconheça seu funcionamento.

Tomar emprestado, como será visto a seguir, termos como cinética, tensão, intensidade do fluxo, difusão facilitada é um procedimento tão mais adequado pelo fato de as disciplinas de que se originam (a mecânica, em especial a dos fluidos, a eletricidade, a biologia celular) os utilizarem em referência a trocas energéticas e de substâncias. Em comum, esses procedimentos referem-se a estabilizações que ocorrem em função de uma diferença, seja 
ela de potencial ou de concentração, existente entre subsistemas colocados em contato. Forças de diferentes intensidades se comunicam e vertem uma em direção à outra, fornecendo à pessoa aflita uma nova configuração de equilíbrio e estabelecendo entre as partes um grau de participação mútuo maior que o inicial.

Em maior ou menor grau, o jarê pode ser visto como um dispositivo de orientação de microcrenças, fluxos de intencionalidades e atenções, voltadas para o estabelecimento não só de canais comunicacionais, como também de vasos comunicantes que alimentam e mantêm vivos os entes do mundo - cujos graus de existência são continuamente variáveis -, incluídas nesse conjunto, ainda que possivelmente longe de serem sua parte mais fundamental, as pessoas que frequentam uma casa. Deste ponto de vista, as pessoas ligadas aos terreiros funcionariam antes de tudo como espécies de relés, por sua capacidade de redirecionar, literalmente através de suas ações, determinados fluxos capazes de enfraquecer ou revitalizar certos entes do mundo. Desse modo, o que está em jogo nas operações que competem a chefes de terreiro é a orientação do sentido dessa força, sendo que, quando encaminhada para um lado, ela é literalmente transportada, levada a deixar sua posição atual, na qual se produzirá necessariamente uma espécie de vácuo. Para as forças do jarê, mais que lados, esquerda e direita seriam antes de tudo sentidos, sendo possível entendê-los enquanto orientados para o esvaziamento ou para a plenitude.

Todo o processo de transferência, entretanto, envolve passagens, gerando tanto espaços mais esvaziados como mais preenchidos. O surgimento desses esvaziamentos energéticos gera enfraquecimento e, no caso dos seres humanos, doenças ou mesmo a morte, cabendo às autoridades que realizam curas o restabelecimento de uma situação menos deficitária, por mais que qualquer equilíbrio atingido seja inevitavelmente provisório. Uma das principais formas de se corrigir essas insuficiências energéticas deriva da propriedade entrópica que possui essa força, que faz com que ela tenda a fluir dos locais onde é mais abundante para onde é mais escassa: neste caso, da chefia do terreiro para sua família-de-santo, mas igualmente das entidades de maneira geral para os seres humanos. ${ }^{6}$

A configuração tensiva desse processo de transferência de energia auxilia a compreensão dos motivos que desaconselham a realização de trabalhos rituais para pessoas que, na expressão do povo do jarê, "já nasceram feitas". Os rituais que qualquer líder de terreiro empreende são realizados partindo da pressuposição de que se irá corrigir uma deficiência energética por meio da abundância de sua força pessoal, aí incluídas as potências de suas entidades, e para tanto são realizadas medidas litúrgicas que auxiliarão 
na tarefa de transferir o excesso de energia no sentido de quem se inicia. Via de regra, líderes de terreiro têm mais experiência em sua manipulação, sabendo modulá-la de forma a obter os efeitos desejados, possuindo-a em maior quantidade, mobilizando-a com mais facilidade. Pode acontecer, entretanto, de este não ser o caso, já que raramente surgem pessoas que desde o nascimento possuem uma força de intensidade considerável e caráter indomável que, mesmo sem qualquer tipo de trabalho ritual em seu favor, já os exibem em grande quantidade. Chefes de jarê mais experientes conseguem reconhecer esta qualidade de determinadas pessoas e as precauções que é preciso tomar para lidar com elas, bem como os benefícios para a potencialização da força de seus terreiros que a presença contínua das mesmas pode trazer. Ao mesmo tempo, sabem que essas pessoas dificilmente, ou mesmo nunca, devem ser iniciadas, justamente em função da força excessiva que têm.

Caso uma autoridade ritual efetue os procedimentos costumeiros mas se depare com alguém que, ao contrário do esperado, apresente ainda mais força que ela, os resultados talvez sejam ser desastrosos: estabelece-se uma espécie de curto-circuito por sobrecarga, no qual a transferência de força ocorre de maneira desmedida, podendo deixar a chefia do terreiro, no mínimo, consideravelmente debilitada. ${ }^{7}$ Ao contrário do que ocorre com mais frequência, nesses casos a aflição que leva uma pessoa a procurar - ou ser levada a - uma autoridade do culto deriva não de uma debilidade, mas sim de uma superabundância energética, que é justamente uma das principais geradoras das loucuras que caracterizam o comportamento de grande parte das pessoas destinadas a realizar, elas próprias, curas. É bastante comum que líderes de terreiro se encontrem fatigados e mesmo carreguem algum tipo de sequela, permanente ou temporária, após a realização de ritos iniciáticos, não sendo coincidência que em grande número de vezes se trate de um efeito que altera a capacidade de locomoção, como inchaços e problemas nos pés, pernas e joelhos. Estas são implicações esperadas do trabalho de cura, considerado por isso mesmo um caminho marcado por caridade e altruísmo, e função da nova configuração de forças estabelecida pelo ritual.

\section{Enganando a morte: a religiosidade voltada para a vida}

A morte é um tema que costuma receber muito menos elaboração no jarê que a vida e os seres vivos. Até por isso, não seria exato considerar a morte como o contrário da vida, já que não passa de parte de seu término, do mesmo modo como o nascimento é seu começo, este sim possivelmente 
oposto ao fim que a morte pode denotar. ${ }^{8}$ Costuma-se comentar que no jarê "tem jeito para tudo, menos para a morte", considerada o momento derradeiro da existência para os seres humanos - ou ao menos para a maior parte deles. A morte, que é ocasionalmente ligada ao mar - "porque o mar é infinito", explicam ${ }^{9}$-, carrega consigo uma grande medida de inevitabilidade, ao mesmo tempo em que suscita conjecturas a respeito do que pode acontecer a uma pessoa depois de seu falecimento.

Enquanto há quem considere que as almas de todos os seres humanos podem viver eternamente num outro domínio da existência, grande parte do povo de santo afirma de modo categórico que para as pessoas não há nada depois da morte, motivo pelo qual não há razão para se ter medo de cemitérios - ao contrário de igrejas, estas sim locais atemorizantes. Vê-se assim que, se a alma de alguém não constitui sua essência, que sobreviveria intacta após a morte, ela é um resquício possível capaz de habitar o mundo por algum tempo e que não é necessariamente deixado por toda pessoa ao falecer, ou "desencarnar", como também se diz. Na linguagem mais usada no âmbito do jarê, trata-se da "sombra", que aqui é definida como um amálgama da pessoa que se foi somada a algo das entidades que a acompanharam em vida.

Uma pessoa após morrer pode ou não deixar no mundo dos vivos uma parcela de si à qual viventes terão acesso caso tenham a capacidade de lidar com esses seres, em geral chamada de "mediunidade", que é desenvolvida também nas cerimônias de jarê e cuja posse costuma ser indicativa da sina de se tornar chefe de terreiro. Além de pessoas que falecem em acidentes naturais ou tragédias, os seres humanos que em vida demonstraram possuir grande força pessoal e que a mobilizaram continuamente tendem a deixar para trás sua sombra, de algum modo sobrevivendo, parcialmente, à própria morte. Nem todo mundo, então, irá necessariamente continuar a existir no além, local onde os espíritos das pessoas que morrem, por vezes chamados de "eguns", habitam, e de onde podem ocasionalmente partir para vir visitar os seres viventes, com resultados diversos. O povo de santo comenta que não é recomendável conceder muita atenção a esses espíritos, já que eles são capazes de se nutrir desses fluxos de intencionalidades e de veicular energia, gerando deficiências que podem ocasionar males a serem curados no jarê. Em função disso, líderes das casas instruem quem frequenta as cerimônias a ignorar seres estranhos que porventura pressinta ou detecte, a fim de não correr o risco de fortalecer um espírito de gente morta e estimulá-lo a permanecer junto aos seres vivos.

As entidades que são próximas de uma pessoa, e de certo modo que também passam a fazer parte de sua composição, podem ter a mesma 
capacidade de sobreviver à morte de quem se inicia no culto, por vezes num grau ainda mais pronunciado. Ao contrário dos seres humanos, dizse, os santos não morrem, por mais que possam com o tempo desaparecer, caso deixem de ser cultuados. A possibilidade de não morrerem é uma das características que distinguem essas entidades da maior parte da humanidade, com exceção das pessoas que tinham deixado o mundo dos vivos sem morrer, ao se "encantarem". Tornando-se habitante de um outro mundo, essa espécie de ex-vivente, por não ter tido de enfrentar a morte, sofre uma transformação peculiar e passa a ter uma constituição que aproxima esse espírito das entidades cultuadas no jarê, muitas das quais podem ser chamadas de maneira intercambiável de "encantados".

Pessoas que encantam, geralmente desaparecendo nas serras ou nas matas, e cujos corpos jamais são encontrados, indicam um fenômeno a ser pensado como inverso ao do já nascer feito: trata-se de pessoas que não serão desfeitas pela morte. ${ }^{10}$ Estas e aquelas que figuram entre os grandes nomes do jarê exibem uma característica que evidencia o cromatismo entre seres humanos, entidades do jarê e espíritos de mortos, já que - em função de sua considerável força pessoal - tanto as pessoas que já nasceram feitas como as que ao longo da vida se tornaram prontas de forma muito intensa são particularmente propensas a se tornarem elas próprias entidades a serem cultuadas - do mesmo modo que pode ter acontecido no passado com a população nativa do continente africano e com indígenas nas Américas, como conjectura parte do povo de santo. Assim como as guiavam em vida, após abandonarem sua existência material, essas pessoas podem continuar a prestar auxílio a viventes que frequentam o jarê, de modo possivelmente não limitado à ação das entidades que deixam para trás e que podem continuar a existir.

O processo mais elaborado de decomposição da pessoa é destinado às grandes autoridades do jarê, às quais deve ser direcionado o já mencionado ritual funerário denominado sirrum, em geral feito alguns anos após seu falecimento, passado um período de luto. O sirrum costuma ser oficiado por outra liderança de terreiro, muitas vezes resultando na desativação completa da casa de culto da pessoa falecida. Como se conta, nessas cerimônias não há toques dos tambores, que permanecem cobertos com panos brancos, sendo a destruição ou a dissolução dos bens de quem se foi a principal atividade do ritual. Fica difícil para quem frequenta a casa conter as lágrimas, ainda que se deva tentar fazê-lo, havendo igualmente a recomendação de que não se deve dar grande atenção a quaisquer visões que se possa ter durante o ritual, comumente da própria pessoa falecida. De todo modo, o fato de que a dissolução de nem toda pessoa precisa ser 
necessariamente completa é mais um dos exemplos que apontam para graus de continuidade entre seres vivos e mortos, humanos e entidades, podendo ser estas também responsáveis pela realização de passagens, atualizando conexões bastante diretas com o domínio da morte.

Este foi o caso de uma criança recém-nascida, filha de uma mulher que deu à luz num terreiro. Uma entidade, Odé - considerado no jarê uma versão infantil de Oxóssi, o orixá da caça -, manifestou-se no curador responsável pela casa e veio saudar a pequenina, perguntando à mãe da criança, em tom de aparente brincadeira, se ela não lhe daria o bebê. Achando alguma graça na situação, e ignorando as consequências de suas palavras - como frisou a senhora que contou esta história -, a mãe disse sim à entidade, que estava fascinada com a beleza da recém-nascida. Pouco tempo depois a criança deixou de se mover, abandonando o mundo vivente, e não ficou dúvida entre quem tinha acompanhado a situação que ela fora levada pela entidade. A partir daí descansaria na "Cidade de Pé-Junto", que é como algumas pessoas se referem ao cemitério, admirável morada na qual toda gente viva repousará um dia, como dizem. Os pés juntos de que falam não se referem apenas ao modo como pessoas mortas são depositadas em seus caixões, mas chamam a atenção também para a principal característica de quem não está mais vivo, a saber, a imobilidade dos pés que não mais sobem e descem as serras dos garimpos, não mais cruzam os rios e as matas, não mais caminham nem dançam.

Todo jarê termina com uma homenagem a Cosme Damião, entidade da gemelaridade e em cujo mês de setembro costuma se concentrar o maior número de cerimônias das mais diversas casas de culto de Lençóis. Há um mito contado no jarê que aproxima Cosme dos Ibêji, orixá duplo africano ligado igualmente aos gêmeos. Segundo essa história, muito tempo atrás havia num reino africano um par de irmãos absolutamente idênticos, já por isso considerados muito especiais. Certo dia, durante uma celebração para as entidades, a Morte chegou ao reino dizendo que iria levar consigo todos os seus habitantes assim que o couro dos atabaques parasse de soar. Diante da sina nefasta, os irmãos tiveram uma ideia e decidiram se revezar nos atabaques, de modo que um pudesse descansar enquanto o outro mantinha a música viva, estendendo indefinidamente a duração da festa. Como eram idênticos e trocavam de lugar quando a Morte se distraía, ela não foi capaz de distingui-los e imaginou que se tratava de uma mesma pessoa tocando ininterruptamente. Cansando-se de esperar, ela finalmente desistiu de seu intento e deixou o reino sem levar ninguém que o habitava. Os gêmeos foram saudados como heróis, vindo eles próprios, posteriormente, a se tornarem divindades. 
De certo modo, todo jarê realizado até os dias de hoje pode ser pensado como uma reatualização desse embate e desse ardil. Como os gêmeos do mito, os tocadores de atabaque são responsáveis por manter a festa sempre em curso, instando, junto com as demais pessoas presentes, o povo de santo a continuar dançando, as entidades a não deixarem o salão, apesar do esgotamento a que todo mundo está inevitavelmente sujeito. Bater jarês é uma forma de fazer com que a vida, em sua plenitude, prossiga, e até por isso as cerimônias são voltadas para a cura e a reabilitação de quem as frequenta, para a mobilização das entidades e das forças que compõem e são compostas pelas pessoas, para o afastamento progressivo dos espíritos de mortos e suas influências perturbadoras. Bater jarês é sobretudo um meio de manter viva uma festa sem fim, uma festa que não pode acabar sem que se corra o risco de seu término significar também o término da vida como a conhecemos. De todo modo, uma festa é - e precisa ser - uma ocasião feliz, animada, muito embora as circunstâncias nem sempre favoreçam a alegria. Mesmo diante de uma série de obstáculos, e convivendo com a possibilidade de que sua realidade venha a desaparecer caso seu empenho não se renove, as pessoas ligadas ao culto optam por uma existência plena de vivacidade. Dão testemunho, assim, não só durante as cerimônias, mas também fora delas, das potências da vida e do movimento. Contra a morte, afirmam as forças do jarê.

Recebido em: 11 de junho de 2018

Aprovado em: 29 de outubro de 2018

Gabriel Banaggia

Doutor em Antropologia Social pelo Museu Nacional da Universidade Federal do Rio de Janeiro, instituição onde também realizou pós-doutorado. Atualmente desenvolve pesquisa de pós-doutorado no Programa de Pós-Graduação em Ciências Sociais da PUC-Rio. Realizou trabalho de campo na Chapada Diamantina pesquisando o jarê, variante do candomblé presente exclusivamente nessa região. Especialista em religiões de matriz africana no Brasil, políticas públicas com recorte étnico-racial e antropologia das populações afro-brasileiras. 


\section{Notas}

1 Este texto é derivado de uma ideia originalmente concebida no âmbito do Grupo de Trabalho sobre Antropologia da Morte, que se reuniu em 2012 na $28^{\mathrm{a}}$ Reunião Brasileira de Antropologia. A respeito desta ocasião, o autor agradece os comentários de Hippolyte Brice Sogbossi. Posteriormente, uma versão mais próxima do que viria a ser este artigo foi apresentada como uma das palestras mensais do Programa de Pós-Graduação em Antropologia Social do Museu Nacional (UFRJ), em 2016, sendo o autor então grato em especial às contribuições de Clara Flaksman e Luisa Elvira Bellaunde. Por fim, registra-se aqui também um agradecimento às sugestões das pessoas responsáveis pelos pareceres anônimos que o texto recebeu.

$2 \mathrm{O}$ autor realizou trabalho de campo durante quase 14 meses (sendo 12 deles consecutivos) na cidade de Lençóis, junto ao povo de santo dos jarês locais, ao qual aproveita a oportunidade para mais uma vez agradecer, em especial às casas Palácio de Ogum e Caboclo Sete-Serra, Águas de Iemanjá e Pai Gil de Ogum. A pesquisa resultou em sua tese de doutorado, posteriormente revisada e publicada como livro (Banaggia 2013, 2015). Os únicos dois outros trabalhos que se dedicaram ao mesmo tema disponíveis à época lidavam ou de modo panorâmico com os jarês de toda a Chapada Diamantina (Senna 1998), ou em profundidade com jarês de um distrito pertencente à zona agrícola (Rabelo 1990). Posteriormente, mais uma tese de doutorado foi defendida, na qual o jarê foi objeto de consideração etnográfica em detalhe (Pedreira 2015).

3 No jarê, de modo bastante singular, praticamente todas as entidades espirituais que visitam os corpos de praticantes durante as cerimônias podem ser concebidas como "caboclos", fenômeno que é fruto de um processo histórico complexo que foge aos objetivos do presente texto. Aqui cabe reter que essa "caboclarização" (Senna 1998:116) de todas as entidades faz com que espíritos que em outros contextos etnográficos são entendidos somente como orixás (a exemplo de Oxalá, Iansã, Xangô) no jarê tenham características de caboclos: puxam suas próprias cantigas, conversam com a congregação e dançam ritmos considerados ligeiros.

4 Termo proposto como forma de transformar para o registro cosmológico o uso que um dos principais cronistas da região faz da expressão "democracia telúrica", conceito usado para se referir ao surgimento de uma sociedade sertaneja que "se plasmou por suas próprias leis" (Moraes 1983:19).

5 Em seu sentido técnico, precipitação é o nome da criação de um sólido a partir de uma solução, frequentemente líquida. Nesse processo, partículas que inicialmente fazem parte de uma mesma substância começam a se destacar do conjunto e ficam em suspensão, e a ação de uma força (como a própria gravidade) ao longo do tempo vincula as partes menores num sólido que recebe o nome de precipitado.

6 Ainda assim, não é o caso de se descartar por completo a existência de uma força efetivamente negativa, uma "antiforça" - no sentido que possui o termo "antimatéria" - responsável não por esvaziamentos, mas sim pela verdadeira aniquilação 
da energia. Essa antiforça, contudo, parece ser domínio exclusivo de entidades muito perigosas e com as quais pouco diálogo é possível, a exemplo das sombras de mortos, das quais se deve procurar sempre manter distância absoluta. Num outro campo etnográfico de matriz africana, as casas de religião da cidade de Pelotas, no extremo sul do Brasil, pode-se usar a expressão "axé de miséria" ou o termo "inxé" para se referir ao simétrico inverso do axé, que guarda claras semelhanças com a antiforça aqui exposta (cf. Barbosa Neto 2012:95-98, 106, 226 nota 200, 274).

7 Uma adepta, por exemplo, informa, de modo aparentemente despretensioso, como todas as pessoas que tentaram realizar algum tipo de cura em benefício dela acabaram mortas pouco tempo depois (Rabelo 1990:178-179).

8 É o que igualmente se depreende do fato de que chefes de terreiros, se podem por vezes invocar e talvez mesmo receber espíritos dos mortos, jamais o fazem durante as cerimônias de jarê, culto cuja "religiosidade está voltada para o mundo dos vivos" (Gonçalves 1984:131, 134).

9 A associação entre o mar e a morte parece ser recorrente nos candomblés angola e em outras religiões de matriz africana, em tudo lembrando, por exemplo, a Kalunga do palo cubano, inclusive no modo como falam a respeito dela, equacionada com o mar: trata-se de um plano de imanência do qual sujeitos e objetos emergem ao sabor das flutuações, das marés (Ochoa 2004:42-53; 2007:482). O termo foi escolhido para fazer parte do nome de uma obra que reúne imagens produzidas ao longo de três séculos a respeito dos negros no Brasil (Moura 2000:15).

10 No candomblé, crianças que são reclamadas para morrer antes mesmo de nascer, ditas abiku, têm sua existência na terra condicionada a uma negociação com as entidades, não devendo por isso ser iniciadas: como aí a iniciação replica uma morte, da qual essas crianças são cotidianamente extraídas, elas não suportariam sofrer uma permeabilização ainda maior a seus efeitos (Augras 1994:77-78 citado em Barbosa Neto 2012:28, nota 20). Apesar de o termo não ser utilizado no jarê, o episódio narrado adiante constitui um exemplo bastante próximo desse fenômeno, cujo desenrolar dramático se processou inteiramente diante dos seres viventes. 


\section{Referências bibliográficas}

AUGRAS, Monique. 1994. "Os gêmeos e a morte: notas sobre os mitos dos ibeji e dos abiku na cultura afro-brasileira". In: Carlos Eugênio Marcondes de Moura (org.), As senhoras do pássaro da noite. São Paulo: Editora da Universidade de São Paulo. pp. 73-84.

BANAGGIA, Gabrie.l 2013. As forças do jarê: movimento e criatividade na religião de matriz africana da Chapada Diamantina. Tese de Doutorado em Antropologia, Universidade Federal do Rio de Janeiro.

. 2015. As forças do jarê, religião de matriz africana da Chapada Diamantina. Rio de Janeiro: Garamond.

BARBOSA NETO, Edgar Rodrigues 2012. A máquina do mundo: variações sobre o politeísmo em coletivos afro-brasileiros. Tese de Doutorado em Antropologia, Universidade Federal do Rio de Janeiro.

BASTIDE, Roger. 2005 [1958]. O candomblé da Bahia (rito nagô). São Paulo: Companhia das Letras.

BRITO, Francisco Emanuel Matos. 2005. Os ecos contraditórios do turismo na Chapada Diamantina. Salvador: Editora da Universidade Federal da Bahia.

ELBEIN DOS SANTOS, Juana. 2002 [1975]. Os nàgô e a morte: pàde, àsèsè e o culto égun na Bahia. Petrópolis: Vozes.

FLAKSMAN, Clara Mariani. 2014. Narrativas, relações e emaranhados: os enredos do candomblé no Terreiro do Gantois, Salvador, Bahia. Tese de Doutorado em Antropologia, Universidade Federal do Rio de Janeiro.

GONÇALVES, Maria Salete Petroni de Castro. 1984. Garimpo, devoção e festa em Lençóis, BA. São Paulo: Escola de Folclore, Prol.
LIMA, Carlos César Uchôa de \& NOLASCO, Marjorie Csekö. 1997. Lençóis, uma ponte entre a geologia e o homem. Salvador: Empresa Gráfica da Bahia.

MORAES, Walfrido. 1997 [1983]. "Prefácio à terceira edição". In: Jagunços e heróis: a civilização do diamante nas lavras da Bahia. Salvador: Empresa Gráfica da Bahia. pp. 19-21.

MOURA, Carlos Eugênio Marcondes de. 2012 [2000]. A travessia da calunga grande: três séculos de imagens sobre o negro no Brasil (1637-1899). São Paulo: Editora da Universidade de São Paulo.

OCHOA, Todd Ramón. 2004. The dead and the living in a Cuban-Kongo sacred society. Tese de Doutorado em Antropologia, Columbia University. PEDREIRA, Carolina Souza. 2015. Tecidos do mundo: almas, espíritos e caboclos em Andaraí, Bahia. Tese de Doutorado em Antropologia, Universidade de Brasília.

RABELO, Miriam. 1990. Play and struggle: dimensions of the religious experience of peasants in Nova Redenção, Bahia. Tese de Doutorado em Ciências Sociais, University of Liverpool.

SENNA, Ronaldo de Salles. 1998. Jarê - uma face do candomblé: manifestação religiosa na Chapada Diamantina. Feira de Santana: Editora da Universidade Estadual de Feira de Santana.

SOUTY, Jérôme. 2007. Pierre Fatumbi Verger: du regard détaché à la connaissance initiatique. Paris: Maisonneuve \& Larose.

TOLEDO, Carlos de Almeida. 2001. A mobilização do trabalho nas Lavras Baianas. Dissertação de Mestrado 
em Geografia Humana, Universidade de São Paulo.

2008. A região das Lavras Baianas.

Tese de Doutorado em Geografia

Humana, Universidade de São Paulo. 


\section{CANALIZAR O FLUXO: LIDANDO COM A MORTE NUMA RELIGIÃO DE MATRIZ AFRICANA}

\section{Resumo}

Este artigo trata das diferentes formas por meio das quais fiéis do jarê, uma religião de matriz africana que só existe na Chapada Diamantina - uma região de colinas íngremes no interior do estado da Bahia, no nordeste do Brasil -, conceitualizam a morte. O tema se conecta de modos complexos com a história e a geografia da área, que por mais de um século gravitou inteiramente em torno das atividades de garimpo de diamantes. O jarê desenvolve um tipo de "metafísica telúrica" segundo a qual o chão, a terra e o ato de caminhar são entretecidos em situações de vida e morte ritualmente elaboradas durante as cerimônias. O jarê exemplifica como a força vital de cada pessoa é concebida como um fluxo instável e direcionável, cuja labilidade é processada de acordo com diferenças de concentração energética efetuadas por ações rituais que podem ter resultados até fatais.

Palavras-chave: Religião afro-brasileira; Jarê; Antropologia da religião; Antropologia da morte; Populações afro-brasileiras.

\section{CHANNELLING THE FLOW: DEALING WITH DEATH IN AN AFRICAN-BASED RELIGION}

\begin{abstract}
This article addresses how the practitioners of jarê, an African-based religion that exists only in the Chapada Diamantina - a region of steep cliffs in the heart of the state of Bahia, northeast Brazil-, conceptualize death. The theme connects in complex ways with the history and the geography of the area, which has, for over a century, gravitated entirely around diamond prospecting activities. Jarê develops a sort of "telluric metaphysics" according to which the ground, the earth and the act of walking are interwoven into situations of life and death that are ritually elaborated during ceremonies. Jarê affirms that the life force of every person is conceived as an unstable and directable flux, the lability of which is processed according to differences in the concentration of energy as effected by ritual actions that can result in the death of participants.
\end{abstract}

Keywords: Afro-Brazilian religion; Jarê; Anthropology of religion; Anthropology of death; Afro-Brazilian peoples. 


\section{CANALIZAR EL FLUJO: LIDIANDO CON LA MUERTE EN UNA RELIGIÓN DE MATRIZ AFRICANA}

\section{Resumen}

Este artículo trata de las diferentes formas por medio de las cuales fieles del jarê, una religión de matriz africana que sólo existe en la Chapada Diamantina - una región de colinas escarpadas en el interior del estado de Bahía, en el nordeste de Brasil -, conceptualizan la muerte. El tema se conecta de modos complejos con la historia y la geografía del área, que por más de un siglo gravitó enteramente en torno a las actividades de extracción de diamantes. El jarê desarrolla un tipo de "metafísica telúrica" según la cual el suelo, la tierra y el acto de caminar se entretejen en situaciones de vida y muerte ritualmente elaboradas durante las ceremonias. El jarê ejemplifica como la fuerza vital de cada persona es concebida como un flujo inestable y direccionable, cuya labilidad es procesada de acuerdo con diferencias de concentración energética efectuadas por acciones rituales que pueden tener, inclusive, resultados fatales.

Palabras clave: Religión afro-brasileña; Jarê; Antropología de la religión; Antropología de la muerte; Poblaciones afrobrasileñas. 